\title{
Selecting the right bird model in experimental studies on endocrine disrupting chemicals
}

\author{
Veerle L. B. Jaspers * \\ Bird Ecotoxicology Group, Department of Biology, Norwegian University of Science and Technology, Trondheim, Norway
}

Birds have been used as model species in ecotoxicological research for decades but have only recently been included in toxicity testing schemes. However, the avian fauna is very diverse. Given this diversity, the ecology, behavior, and reproduction should be considered when selecting the appropriate bird model in ecotoxicological studies. This article focusses on choosing the right bird model species for experimental studies with endocrine disrupting chemicals (EDCs). EDCs have been associated with adverse effects

OPEN ACCESS

Edited by:

David Delmail,

University of Rennes 1, France

Reviewed by:

Marco Lemos,

Polytechnic Institute of Leiria, Portugal

Alexa C. Alexander,

Environment Canada, Canada

*Correspondence:

Veerle L. B. Jaspers,

Department of Biology, Norwegian University of Science and Technology,

Realfagbygget EU2-169,

Høgskoleringen 5, 7491 Trondheim,

Sør-Trøndelag, Norway

veerle.jaspers@ntnu.no

Specialty section:

This article was submitted to

Environmental Toxicology,

a section of the journal

Frontiers in Environmental Science

Received: 03 February 2015

Accepted: 17 April 2015

Published: 05 May 2015

Citation:

Jaspers VLB (2015) Selecting the right bird model in experimental studies on endocrine disrupting chemicals.

Front. Environ. Sci. 3:35.

doi: 10.3389/fenvs.2015.00035 on reproduction and development in birds and other wildlife. In addition, new EDCs continue to emerge and the concern for potential effects in humans and wildlife is calling for increased toxicity testing and hence appropriate model species. Common bird model species used in ecotoxicological studies investigating EDCs will be reviewed. In addition, considerations for selecting the right bird model, along with potential drawbacks and restrictions on the use of certain species will be discussed.

Keywords: bird models, endocrine disruption, animal models, poultry, songbirds, raptors

\section{Introduction}

\section{Endocrine Disrupting Chemicals and Ecotoxicology}

Endocrine disrupting chemicals (EDCs) are chemicals that can interfere with the hormone homeostasis in the body (Colborn et al., 1993). These include organochlorine pesticides, dioxins and furans, polychlorinated biphenyls (PCBs), phthalates, brominated flame retardants, and some metals including lead, mercury, and cadmium (Crisp et al., 1998; Meerts et al., 2001; Jiménez et al., 2007). Disruption of hormone systems, causing effects on e.g., reproductive hormones, the thyroid system, immune system or neurobehavioural development, can have far-reaching consequences for reproduction and development. Evidence of such effects in birds, fish, and other wildlife has also increased concern about potential endocrine disruptive effects in humans (Stokes, 2004). In addition, worst case scenarios in arctic birds and mammals under changing climate conditions have been discussed, as EDCs may interfere with adaptation to increased stress situations (Jenssen, 2006). Although many of the traditional EDCs have been banned or restricted in their use by the Stockholm Convention on Persistent Organic Pollutants (UNEP, 2009), emerging chemicals with EDC potential, such as bisphenol A and new flame retardants, are produced and can be found in the environment (Sauvé and Desrosiers, 2014). The focus of ecotoxicological research is to investigate and predict the fate of these as well as other environmental contaminants in the environment, their bioavailability, uptake in organisms, toxicokinetics, and potential effects. Ecotoxicological risk assessment is an important part of current legislative frameworks (such as the European 
REACH $^{1}$ framework, the US Toxic Substances Control Act and the Pollution Prevention Act) regarding chemical production and use. Recently there is also much focus on the use of in vitro models as alternatives to animal testing (Menache and Nastrucci, 2012). However, in many cases, tests on live animals are still required, particularly to fill the knowledge gap concerning effects of EDCs on altered physiology, and on behaviors related to reproduction, cognition, and memory (LeónOlea et al., 2014). Furthermore, ecotoxicological research is not only concerned about effects on the individual level, but considers also population effects that may affect other species higher in the food chain (Stokes, 2004; Casarett and Klaassen, 2008).

According to Kendall et al. (2010), the fact that EDCs continue to emerge, will also increase the demand for wildlife studies examining their effects. Following the same line of thinking, the need for appropriate animal models (both for field and laboratory studies) will also increase.

\section{General Considerations When Choosing an Animal Model}

Assessing the potential adverse effects of EDCs on wildlife (or humans) requires the use of surrogate (model) species, from which extrapolations can be made to other species (Stokes, 2004). Choosing the right animal model for ecotoxicological research is dependent on the type of study (monitoring vs.experimental). In general, model species should be representative for their environment in the best possible way (Persoone and Gillette, 1990). Species that are widespread, long-lived, and well-known in terms of their physiology, ecology, and behavior are therefore of interest (Burger, 1993). However, for laboratory experiments, there is a lack of ecological information needed to establish laboratory populations, which is a serious handicap for increasing the variety of potential candidate species (Persoone and Gillette, 1990). Species with low ecological needs, meaning ease of housing and care-taking, a short life-cycle, known genetic background, and standard diet, are preferred. Field studies on the other hand, may have other preset conditions and requirements than controlled laboratory studies, and must take into consideration, for example, longevity, residency, habitat, abundance, and accessibility (e.g., Patuxent Wildlife Research Centre POP Utility Index by Golden et al., 2003). Furthermore, the approach to study impacts of chemicals in terrestrial and aquatic ecosystems is very different, because of the different modes of exposure of biota to chemicals in those environments (Persoone and Gillette, 1990; Hem et al., 2001). Terrestrial biota mostly take up contaminants via food or inhalation, while for aquatic animals absorption from the water through the skin and the gills should be taken into account as important pathways for contaminant exposure.

The choice of the animal model should also be in accordance with the sample type and amount that needs to be obtained in order to meet the research objectives in the best possible way. This choice is dependent on the specific study endpoints, the

${ }^{1}$ REACH. Website: http://ec.europa.eu/enterprise/sectors/chemicals/reach/index en.htm analytical methods, but also species-specific characteristics. For example, to study the tissue distribution of PCBs in birds, one needs to select a species that is large enough in order to obtain enough sample material from each individual tissue required for analysis.

Irrespective of the animal model that is selected for an experiment, it is of utmost importance to obtain animals that are in good health (Fox et al., 1979). Standardization and genetic integrity are key factors to obtain accurate and reproducible results (Fox et al., 1979; Hem et al., 2001). It is thus important to use animals from the same supplier throughout the study. It should also be evaluated if animals from the same age or sex can be used in the experiment to reduce confounding variation (Hem et al., 2001). Factors that can further influence the choice of the specific animal model are practical considerations such as ease of handling, sampling, and housing. In addition, ethical issues can have an influence on the choice of the animal model as well. For example, monkeys, cats, and dogs are preferably not used for animal experiments and require specific conditions (Hem et al., 2001). For birds, raptors can only be used for experiments when they have been bred in special facilities and with special permission. The use of wild-caught birds should be avoided, owing to animal welfare considerations and disease control (OECD, 2010).

\section{Birds as Animal Model Species in Experimental Studies on EDCs}

Golden and Rattner (2003) investigated the suitability of different terrestrial vertebrates in ecotoxicological monitoring studies of various environmental contaminants. The authors found that no single species, taxa or class of vertebrates was an ideal sentinel for all groups of contaminants, although birds have overwhelmingly been used compared to other vertebrate classes.

While rats and mice have been used extensively for the purpose of human risk assessment, birds have been used since the 1960s in ecotoxicological studies because they have several characteristics that make them highly suitable for this kind of research (Burger, 1993; Smits and Fernie, 2013). Due to a variety of different factors, including worldwide distribution, migratory abilities, diverse foraging habits, their conspicuous nature, and their sensitivity to environmental pollutants, contaminant exposure has been better documented in birds than in any other terrestrial vertebrate group (Golden and Rattner, 2003; Smith et al., 2007). In addition, the ecology, physiology, and behavior of many bird species have been well studied, which helps to interpret results and to design experiments. Besides, the avian embryo can be easily visualized while it grows by candling the eggs (Burnham, 1983; Weaver and Cade, 1985). This feature makes birds highly valuable for the study of developmental biology and toxicology (Huss et al., 2008). Toxicologists have taken advantage of the accessibility and relative isolation of the avian embryo for testing a variety of compounds as well as exposure to the embryo from maternal deposition (Ottinger et al., 2002). 
Most studies in birds have focused on traditional toxicological tests, with little attention to non-lethal effects. Consequently, it has proven difficult to assess potential risks associated with exposure to EDCs, where low dose and chronic exposures are more relevant (Ottinger et al., 2013). This is further complicated by the great variation that occurs across avian species, including variations in reproductive strategies, life span, sexual differentiation, and migration (Ottinger et al., 2013). Therefore, species belonging to different groups of birds are preferred model species for different types of studies. This will be discussed in the sections below, highlighting for each group some examples of species that have successfully been used for different types of studies.

\section{Poultry}

Pesticide registration in Europe (OECD, 2010) and the United States (Hoffman et al., 1990) has traditionally used acute oral toxicity tests on mallard ducks (Anas platyrhynchos), northern bobwhite quail (Colinus virginianus), and Japanese quail (Coturnix japonica). On the other hand, the use of chickens (Gallus gallus domesticus) has been mostly directed toward specific ocular- and neurotoxicity tests (OECD, 2009, 2013; Toxicity testing methods, 2013). Although the bobwhite quail has frequently been the avian species selected for toxicity testing, relatively few data have been collected on the neuroendocrine regulation of reproduction in this species. This makes studies of EDCs difficult in this species. On the other hand, a great deal is known about neuroendocrine regulation of reproduction in the Japanese quail (Ottinger et al., 2005).

The Japanese quail has been a popular animal model in numerous fields of research since the 1950s (Padgett and Ivey, 1959). The quail's developmental period of 16 days and its easily accessible embryo make $C$. japonica a convenient model for studies of developmental biology and ecotoxicology (Huss et al., 2008). In addition, C. japonica has a sexual maturation period of 8 weeks, resulting in generational times that are substantially shorter than those of chickens. In addition, the small body size of the adult quail optimizes animal husbandry space and cost (Huss et al., 2008). Different quail lines with specific genetic or phenotypic characteristics are available and recently the quail has proven to be a successful model for the production of a transgenic bird (Huss et al., 2008; Shin et al., 2014). Moreover, the Japanese quail has proven usefulness in studies of the reproductive toxicology of chemical compounds and the effects of environmental EDCs (Ottinger et al., 2005; Li et al., 2013). For example, studies of three common EDCs, estradiol, methoxychlor, and DDE, have shown effects on male sexual behavior, neuroendocrine regulation of reproduction, and reduced hen fertility (Ottinger et al., 2005). In addition, effects of the flame retardant Dechlorane Plus on liver enzyme activities and the induction of oxidative stress have been reported in Japanese quails (Li et al., 2013). Still, there is a need for the development of improved husbandry and handling procedures to reduce confounding behaviors, unintended morbidity and mortality, as well as a need to determine the genetic strain with the most appropriate attributes and sensitivities for EDC testing (Touart, 2004).

\section{Precocial vs. Altricial Species}

Although a lot of research has been focused on poultry, there are dramatic differences, both in reproductive strategies and lifetime reproductive patterns across avian species (Starck and Ricklefs, 1997). Precocial species such as quail produce hatchlings that are well developed. In contrast, passerine birds (songbirds) are generally altricial, with hatchlings dependent on intensive parental care. Precocial species appear to have a much more limited critical period in which gonadal steroids affect sexual differentiation of the brain. Conversely, altricial species have a more gradual developmental period in terms of sexual behavior and song (Ottinger et al., 2002). As such, the gender-dimorphic neural song areas in the brain of many songbirds appear to be structurally affected by steroid hormones throughout their life (Nottebohm and Arnold, 1976; Ottinger et al., 2002). Consequently, the response of altricial species to EDCs may be more difficult to characterize due to this flexibility (caused by neural plasticity). It may ultimately be that passerines are less likely to be impacted by EDCs as embryos, but may be sensitive to EDC effects throughout life (Ottinger et al., 2002, 2013). Ottinger et al. (2002) discuss that sporadic exposure to EDCs might temporarily impair reproductive function more in an adult passerine compared to a precocial species. Conversely, if a precocial species is EDC-exposed as an embryo or perinatally, these birds may suffer permanent reproductive impairment. Therefore, it is important to determine brain vs. gonad effects and compare differential responses in precocial and altricial species (Ottinger et al., 2002). In addition, it is important to consider thyroid active EDCs because exposed birds may be less resilient to environmental conditions and challenges, involving temperature regulation or metabolic adjustments (McNabb, 1989). However, developmental patterns of thyroid function are markedly different in precocial vs. altricial birds (Ottinger et al., 2013). In contrast to precocial species, altricial birds show very little histological or functional thyroid development during embryonic life or the perihatch period (Ottinger et al., 2013) and thus seem less likely to be impacted by thyroid active EDCs during embryonic development.

\section{Songbirds}

Although there is a vast literature on sexual differentiation and the modulation of the song system in birds, studying the potential impacts of EDCs on altricial birds has been more difficult (Ottinger et al., 2013). Difficulties have arisen with developing effective exposure methods, and some alternative methods have been developed (Ottinger et al., 2013), such as using silastic implants (Van den Steen et al., 2007, 2009). In addition, the ongoing neural plasticity during adulthood in songbirds (see above), further complicates the assessment of long term effects of EDCs. Songbirds that have been frequently used in laboratory ecotoxicological research are, for example, zebra finches (Taeniopygia guttata) and European starlings (Sturnus vulgaris). Millam et al. (2002) have assessed the growth response of zebra finch chick oviducts to oral estrogens. They concluded that this measure can be used as a sensitive avian bioassay for environmental estrogens and is particularly relevant for passerine 
species, in which sexual differentiation may remain sensitive to estrogen perturbation after, as well as before, hatching (Millam et al., 2002). The drawback of working with zebra finches is that they are small and thus a limited amount of sample can be obtained from each individual. Starlings can be studied both in the field using artificial nest boxes, in outdoor aviaries, and under laboratory conditions. Because of their ease of study under field conditions using nest boxes, starlings have shown to be a valuable avian model for field studies of pesticides (Hoffman et al., 2003). They consume soil invertebrates which come in direct contact with the pesticides in the soil. Furthermore, starlings have also been used in exposure studies for EDCs, both in outdoor aviaries (Van den Steen et al., 2009) as well as exposure of nestlings in the field and subsequent transfer to the laboratory (Eng et al., 2014). Other passerines that have often been used in linking exposure to effects in a field context are great tits (Parus major), pied flycatchers (Ficedula hypoleuca), and tree swallows (Tachycineta bicolor) (see for example Rainio et al., 2013; Gilchrist et al., 2014; Cruz-Martinez et al., 2015a; Vermeulen et al., 2015).

\section{Birds of Prey}

A last group of birds which are of high importance are birds of prey. Birds of prey are especially important because of their high position in the food chain, making them very sensitive to the biomagnification of chemicals (Furness, 1993). Birds of prey have, however, a protected status in most countries, and due to legislative, ethical, and practical considerations are not routinely used in laboratory experiments. However, some research institutes have their own in-house colonies of, for example, American kestrels (Falco sparverius) or can get access to birds from falconry. Knowledge and experience in housing and breeding these birds in captivity is of utmost importance. For example, Pattee et al. (1981) investigated experimental leadshot poisoning in five bald eagles (Haliaeetus leucocephalus) from a wildlife rescue center that were unsuitable for release or captive breeding, and were thus available for research purposes. However, the species most often used so far in dietary exposure studies has been the American kestrel, both for acute toxicity (Rattner et al., 2011), reproductive toxicity (Lincer, 1975; Fernie et al., 2009, 2011; Sullivan et al., 2013), immunotoxicity (Fernie et al., 2005; Cruz-Martinez et al., 2015b), and endocrine disruption research (Love et al., 2003). In addition, exposure experiments with emerging contaminants have recently highlighted endocrine disrupting properties in American kestrels (Marteinson et al., 2011a,b).

Since the effects of toxicants in free-living birds of prey can be used as an early warning system for the whole ecosystem (Woodruff, 2011), birds of prey are commonly used in monitoring programs (Gómez-Ramírez et al., 2014) using non-destructive sampling methods (Dell'Omo et al., 2008; Pereira et al., 2009; Eulaers et al., 2011; Jaspers et al., 2011; Johansson et al., 2011; Gómez-Ramírez et al., 2012; García-Fernández et al., 2013). Therefore, experimental exposure studies on birds of prey, although difficult and scarce, are of utmost significance to predict effects in free-living birds of prey.

\section{How to Select the Best Bird Model}

Table 1 presents an overview of considerations and criteria one should take into account when selecting an appropriate model species for experiments in ecotoxicology. Firstly, the choice of the right animal model is mostly dependent on the research question. As the avian class is a very diverse group of species with different ecological and reproductive strategies, the specific objectives of the study determine which species is most suitable. If immediate effects of EDC exposure during embryonic development are of interest, the Japanese quail may be a good model species. If however, effects on brain development later in life are considered,

TABLE 1 | Considerations to be made when selecting the best bird model for ecotoxicological studies, in order of importance.

\begin{tabular}{|c|c|c|}
\hline Considerations & Selection criteria & Examples \\
\hline \multirow{4}{*}{$\begin{array}{l}\text { Objectives of the } \\
\text { study }\end{array}$} & - Ecological relevance & - Kestrels as top predators- Starlings (extrapolations lab to field studies)- Aquatic (e.g., mallard, duck) \\
\hline & - Human relevance & - Poultry as food- Species high on the food chain (e.g, kestrels) \\
\hline & - Early developmental effects & Precocial species, e.g., quails \\
\hline & - Effects later in life & Altricial sp. e.g., zebrafinch \\
\hline
\end{tabular}

Practical - Experience with a species

considerations

$\begin{array}{ll}\text { - Sensitivity of a species } & \text { Derived from previous experience or published literature } \\ \text { - Easy to keep / handle } & \text { e.g., Poultry } \\ \text { - Costs of keeping a species } & \text { Larger species require generally more space, more food and more time to develop } \\ \text { - Size of the bird } & \text { e.g., Small passerines, younger birds } \\ \text { - Sample type and amount } & \text { e.g., More blood can be obtained from larger species } \\ \text { - Ethical and legal issues } & \text { Difficult to use birds of prey }\end{array}$

Reducing confounding factors
- Genetic variability- Standardized diet e.g., Same poultry breedernot available for all species

Age and gender Using chicks 
songbirds such as zebra finches may be a better choice. In addition, factors such as experience in handling and keeping a certain species, ethical considerations, and legal frameworks become important. Furthermore, the amount of sample (for example blood or tissue) needed for analysis may be of concern when choosing the right model species. Ecological relevance and the position in the food chain are also factors that should be considered when choosing a model species, but experiments on birds of prey are rare and difficult, and require large experience with holding the study species in captivity. Lastly, the importance of reducing confounding factors (suitable diet, minimum genetic variability, age, and sex of the birds) should be taken into account.

\section{Acknowledgments}

Thanks to Dr. Pilar Gómez-Ramírez from the University of Murcia and Prof. Cynthia de Wit from Stockholm University for proofreading the manuscript. Mari Engvig Løseth and Nathalie Briels are acknowledged for sharing relevant literature. Dr. Veerle Jaspers is financially supported by the Norwegian University of Science and Technology (NTNU). This manuscript is based on an essay written during Dr. Jaspers' student participation in the Laboratory Animal course organized at NTNU in November 2014 (course responsible Siv Eggen).

\section{References}

Burger, J. (1993). Metals in avian feathers: bioindicators of environmental pollution. Rev. Environ. Toxicol. 5, 203-311.

Burnham, W. (1983). Artificial incubation of falcon eggs. J. Wildl. Manage. 47, $158-168$.

Casarett, L. J., and Klaassen, C. D. (2008). Casarett and Doull's Toxicology: The Basic Science of Poisons, 7th Edn. New York, NY: McGraw-Hill Medical.

Colborn, T., Saal, F. S. V., and Soto, A. M. (1993). Developmental effects of endocrine-disrupting chemicals in wildlife and humans. Environ. Health Perspect. 101, 378-384. doi: 10.2307/3431890

Crisp, T. M., Clegg, E. D., Cooper, R. L., Wood, W. P., Anderson, D. G., Baetcke, K. P., et al. (1998). Environmental endocrine disruption: an effect assessment and analysis. Environ. Health Perspect. 106, 11-56.

Cruz-Martinez, L., Fernie, K. J., Soos, C., Harner, T., Getachew, F., and Smits, J. E. G. (2015a). Detoxification, endocrine, and immune responses of tree swallow nestlings naturally exposed to air contaminants from the Alberta oil sands. Sci. Total Environ. 502, 8-15. doi: 10.1016/j.scitotenv. 2014.09.008

Cruz-Martinez, L., Smits, J. E. G., and Fernie, K. (2015b). Stress response, biotransformation effort, and immunotoxicity in captive birds exposed to inhaled benzene, toluene, nitrogen dioxide, and sulfur dioxide. Ecotoxicol. Environ. Saf. 112, 223-230. doi: 10.1016/j.ecoenv.2014.10.016

Dell'Omo, G., Costantini, D., Wright, J., Casagrande, S., and Shore, R. F. (2008). PCBs in the eggs of Eurasian kestrels indicate exposure to local pollution. Ambio 37, 452-456. doi: 10.1579/0044-7447(2008)37[455:PITEOE]2.0.CO;2

Eng, M. L., Elliott, J. E., and Williams, T. D. (2014). An assessment of the developmental toxicity of BDE-99 in the European starling using an integrated laboratory and field approach. Ecotoxicology 23, 1505-1016. doi: 10.1007/s10646-014-1292-9

Eulaers, I., Covaci, A., Hofman, J., Nygård, T., Halley, D. J., Pinxten, R., et al. (2011). A comparison of non-destructive sampling strategies to assess the exposure of white-tailed eagle nestlings (Haliaeetus albicilla) to persistent organic pollutants. Sci. Total Environ. 410-411, 258-265. doi: 10.1016/j.scitotenv.2011.09.070

Fernie, K. J., Marteinson, S. C., Bird, D. M., Ritchie, I. J., and Letcher, R. J. (2011). Reproductive changes in american kestrels (Falco sparverius) in relation to exposure to technical hexabromocyclododecane flame retardant. Environ. Toxicol. Chem. 30, 2570-2575. doi: 10.1002/etc.652

Fernie, K. J., Mayne, G., Shutt, J. L., Pekarik, C., Grasman, K. A., Letcher, R. J., et al. (2005). Evidence of immunomodulation in nestling American kestrels (Falco sparverius) exposed to environmentally relevant PBDEs. Environ. Pollut. 138, 485-493. doi: 10.1016/j.envpol.2005.04.008

Fernie, K. J., Shutt, J. L., Letcher, R. J., Ritchie, I. J., and Bird, D. M. (2009). Environmentally relevant concentrations of DE-71 and HBCD alter eggshell thickness and reproductive success of American kestrels. Environ. Sci. Technol. 43, 2124-2130. doi: 10.1021/es8027346

Fox, J. G., Thibert, P., Arnold, D. L., Krewski, D. R., and Grice, H. C. (1979). Toxicology studies. II. The laboratory animal. Food Cosmet. Toxicol. 17, 661-675. doi: 10.1016/0015-6264(79)90127-5

Furness, R. W. (1993). "Birds as monitors of pollutants," in Birds as Monitors of Environmental Change, ed R. W. Furness and J. J. D. Greenwood (London: Chapman and Hall), 86-143.

García-Fernández, A. J., Espín, S., and Martínez-López, E. (2013). Feathers as a biomonitoring tool of polyhalogenated compounds: a review. Environ. Sci. Technol. 47, 3028-3043. doi: 10.1021/es4033869

Gilchrist, T. T., Letcher, R. J., Thomas, P., and Fernie, K. J. (2014). Science of the total environment polybrominated diphenyl ethers and multiple stressors in $\mathrm{fl}$ uence the reproduction of free-ranging tree swallows (Tachycineta bicolor) nesting at wastewater treatment plants. Sci. Total Environ. 472, 63-71. doi: 10.1016/j.scitotenv.2013.10.090

Golden, N. H., and Rattner, B. A. (2003). Ranking terrestrial vertebrate species for utility in biomonitoring and vulnerability to environmental contaminants. Rev. Environ. Contam. Toxicol. 176, 67-136. doi: 10.1007/978-1-4899-7283-5_2

Golden, N. H., Rattner, B. A., and Cohen, J. B. (2003). Ranking Terrestrial Vertebrate Species for Utility in Biomonitoring and Vulnerability to Environmental Contaminants. Laurel, MD: U. S. Geological Survey, Patuxent Wildlife Research Center. Available online at: https://www.pwrc.usgs.gov/ contaminants-online/pages/RankingProgram/RPprogram.htm (Accessed January 19 2015).

Gómez-Ramírez, P., Martínez-López, E., García-Fernández, A. J., Zweers, A. J., and Van den Brink, N. W. (2012). Organohalogen exposure in a Eurasian Eagle owl (Bubo bubo) population from Southeastern Spain: temporal-spatial trends and risk assessment. Chemosphere 88, 903-911. doi: 10.1016/j.chemosphere.2012.03.014

Gómez-Ramírez, P., Shore, R. F., van den Brink, N. W., van Hattum, B., Bustnes, J. O., Duke, G., et al. (2014). An overview of existing raptor contaminant monitoring activities in Europe. Environ. Int. 67, 12-21. doi: 10.1016/j.envint.2014.02.004

Hem, A., Eide, D. M., Engh, E., and Smith, A. (2001). Laboratory Animal Science. Oslo: Norwegian School of Veterinary Science.

Hoffman, D., Rattner, B., and Hall, R. (1990). Wildlife toxicology. Environ. Sci. Technol. 24, 276-283. doi: 10.1021/es00073a001

Hoffman, D. J., Rattner, B. A., Burton, G. A. Jr., and Cairns, J. J. (2003). Handbook of Ecotoxicology, 2nd Edn. Boca Raton, FL: CRC Press.

Huss, D., Poynter, G., and Lansford, R. (2008). Japanese quail (Coturnix japonica) as a laboratory animal model. Lab Anim. (NY) 37, 513-519. doi: 10.1038/laban1108-513

Jaspers, V. L. B., Rodriguez, F. S., Boertmann, D., Sonne, C., Dietz, R., Rasmussen, L. M., et al. (2011). Body feathers as a potential new biomonitoring tool in raptors: a study on organohalogenated contaminants in different feather types and preen oil of West Greenland white-tailed eagles (Haliaeetus albicilla). Environ. Int. 37, 1349-1356. doi: 10.1016/j.envint.2011.06.004

Jenssen, B. M. (2006). Endocrine-disrupting chemicals and climate change: a worst-case combination for arctic marine mammals and seabirds? Environ. Health Perspect. 114, 76-80. doi: 10.1289/ehp.8057

Jiménez, B., Mori, G., Concejero, M. A., Merino, R., Casini, S., and Fossi, M. C. (2007). Vitellogenin and zona radiata proteins as biomarkers of endocrine disruption in peregrine falcon (Falco peregrinus). Chemosphere 67, S375-S378. doi: 10.1016/j.chemosphere.2006.05.131 
Johansson, A. K., Sellstrom, U., Lindberg, P., Bignert, A., and de Wit, C. A. (2011). Temporal trends of polybrominated diphenyl ethers and hexabromocyclododecane in Swedish Peregrine Falcon (Falco peregrinus peregrinus) eggs. Environ. Int. 37, 678-686. doi: 10.1016/j.envint.2011.01.010

Kendall, R. J., Lacher, T. E., Cobb, G. P., and Cox, S. B. (2010). Wildlife Toxicology: Emerging Contaminant and Biodiversity Issues. Boca Raton, FL: CRC Press, Taylor \& Francis Group.

León-Olea, M., Martyniuk, C. J., Orlando, E. F., Ottinger, M. A., Rosenfeld, C. S., Wolstenholme, J. T., et al. (2014). Current concepts in neuroendocrine disruption. Gen. Comp. Endocrinol. 203, 158-173. doi: 10.1016/j.ygcen.2014.02.005

Li, Y., Yu, L., Zhu, Z., Dai, J., Mai, B., Wu, J., et al. (2013). Accumulation and effects of 90-day oral exposure to Dechlorane Plus in quail (Coturnix coturnix). Environ. Toxicol. Chem. 32, 1649-1654. doi: 10.1002/etc.2202

Lincer, J. L. (1975). DDE-induced eggshell-thinning in the american kestrel: a comparison of the field situation and laboratory results. J. Appl. Ecol. 12, 781-793. doi: 10.2307/2402090

Love, O. P., Shutt, L. J., Silfies, J. S., Bortolotti, G. R., Smits, J. E. G., and Bird, D. M. (2003). Effects of dietary PCB exposure on adrenocortical function in captive American kestrels (Falco sparverius). Ecotoxicology 12, 199-208. doi: 10.1023/A:1022502826800

Marteinson, S. C., Kimmins, S., Bird, D. M., Shutt, J. L., Letcher, R. J., Ritchie, I. J., et al. (2011a). Embryonic exposure to the polybrominated diphenyl ether mixture, DE-71, affects testes and circulating testosterone concentrations in adult American kestrels (Falco sparverius). Toxicol. Sci. 121, 168-176. doi: 10.1093/toxsci/kfr02

Marteinson, S. C., Kimmins, S., Letcher, R. J., Palace, V. P., Bird, D. M., Ritchie, I. J., et al. (2011b). Diet exposure to technical hexabromocyclododecane (HBCD) affects testes and circulating testosterone and thyroxine levels in American kestrels (Falco sparverius). Environ. Res. 111, 1116-1123. doi: 10.1016/j.envres.2011.08.006

McNabb, F. M. A. (1989). "Development and aging of the thyroid in homeotherms," in Development, Maturation and Senescence of Neuroendocrine Systems: A Comparative Approach, eds M. P. Schreibman and C. G. Scanes (New York, NY: Academic Press), 333-352

Meerts, I. A. T. M., Letcher, R. J., Hoving, S., Marsh, G., Bergman, A., Lemmen, J. G., et al. (2001). In vitro estrogenicity of polybrominated diphenyl ethers, hydroxylated PBDEs, and polybrominated bisphenol A compounds. Environ. Health Perspect. 109, 399-407. doi: 10.1289/ehp.01109399

Menache, A., and Nastrucci, C. (2012). REACH, animal testing, and the precautionary principle. Medicoleg. Bioeth. 2, 13-29. doi: 10.2147/MB.S33044

Millam, J. R., Craig-Veit, C. B., Batchelder, M. E., Viant, M. R., Herbeck, T. M., and Woods, L. W. (2002). An avian bioassay for environmental estrogens: the growth response of zebra finch (Taeniopygia guttata) chick oviduct to oral estrogens. Environ. Toxicol. Chem. 21, 2663-2668. doi: 10.1002/etc.5620211219

Nottebohm, F., and Arnold, A. P. (1976). Sexual dimorphism in vocal control areas of the songbird brain. Science 194, 211-213. doi: 10.1126/science.959852

OECD. (2009). Test No. 438: Isolated Chicken Eye Test Method for Identifying Ocular Corrosives and Severe Irritants, OECD Guidelines for the Testing of Chemicals, Section 4, Paris: OECD Publishing. doi: 10.1787/9789264076310-en

OECD. (2010). Test No. 223: Avian Acute Oral Toxicity Test, OECD Guidelines for the Testing of Chemicals, Section 2, Paris: OECD Publishing. doi: 10.1787/ 9789264090897-en

OECD. (2013). Test No. 438: Isolated Chicken Eye Test Method for Identifying i) Chemicals Inducing Serious Eye Damage and ii) Chemicals Not Requiring Classification for Eye Irritation or Serious Eye Damage, OECD Guidelines for the Testing of Chemicals, Section 4, Paris: OECD Publishing. doi: 10.1787/9789264203860-en

Ottinger, M. A., Abdelnabi, M., Quinn, M., Golden, N., Wu, J., and Thompson, N. (2002). Reproductive consequences of EDCs in birds What do laboratory effects mean in field species? Neurotoxicol. Teratol. 24, 17-28. doi: 10.1016/S08920362(01)00195-7

Ottinger, M. A., Carro, T., Bohannon, M., Baltos, L., Marcell, A. M., McKernan, M., et al. (2013). Assessing effects of environmental chemicals on neuroendocrine systems: potential mechanisms and functional outcomes. Gen. Comp. Endocrinol. 190, 194-202. doi: 10.1016/j.ygcen.2013.06.004

Ottinger, M. A., Quinn, M. J., Lavoie, E., Abdelnabi, M. A., Thompson, N., Hazelton, J. L., et al. (2005). Consequences of endocrine disrupting chemicals on reproductive endocrine function in birds: establishing reliable end points of exposure. Domest. Anim. Endocrinol. 29, 411-419. doi: 10.1016/j.domaniend.2005.02.038

Padgett, C. A., and Ivey, W. D. (1959). Coturnix quail as a laboratory research animal. Science 129, 267-268. doi: 10.1126/science.129.3344.267

Pattee, O. H., Wiemeyer, S. N., Mulhern, B. M., Sileo, L., and Carpenter, J. W. (1981). Experimental lead-shot poisoning in bald eagles. J. Wildl. Manage. 45, 806-810. doi: $10.2307 / 3808728$

Pereira, M. G., Walker, L. A., Wright, J., Best, J., and Shore, R. F. (2009). Concentrations of polycyclic aromatic hydrocarbons (PAHs) in the eggs of predatory birds in britain. Environ. Sci. Technol. 43, 9010-9015. doi: 10.1021/ es 901805 e

Persoone, G., and Gillette, J. (1990). "Toxicological versus Ecotoxicological Testing," in Short-term Toxicity Tests for Non-genotoxic Effects, eds P. Bourdeau, E. Somers, G. M. Richardson and J. R. Hickman (Chichester: John Wiley \& Sons Ltd), 287-299.

Rainio, M. J., Kanerva, M., Salminen, J. P., Nikinmaa, M., and Eeva, T. (2013). Oxidative status in nestlings of three small passerine species exposed to metal pollution. Sci. Total Environ. 454-455, 466-473. doi: 10.1016/j.scitotenv.2013.03.033

Rattner, B. A., Horak, K. E., Warner, S. E., Day, D. D., Meteyer, C. U., Volker, S. F., et al. (2011). Acute toxicity, histopathology, and coagulopathy in American kestrels (Falco sparverius) following administration of the rodenticide diphacinone. Environ. Toxicol. Chem. 30, 1213-1222. doi: 10.1002/ etc. 490

Sauvé, S., and Desrosiers, M. (2014). A review of what is an emerging contaminant. Chem. Cent. J. 8:15. doi: 10.1186/1752-153X-8-15

Shin, S., Choi, Y. M., Han, J. Y., and Lee, K. (2014). Inhibition of lipolysis in the novel transgenic quail model overexpressing G0/G1 switch gene 2 in the adipose tissue during feed restriction. PLOS ONE 9:e100905. doi: 10.1371/journal.pone. 0100905

Smith, P. N., Cobb, G. P., Godard-Codding, C., Hoff, D., McMurry, S. T., Rainwater, T. R., et al. (2007). Contaminant exposure in terrestrial vertebrates. Environ. Pollut. 150, 41-64. doi: 10.1016/j.envpol.2007.06.009

Smits, J. E. G., and Fernie, K. J. (2013). Avian wildlife as sentinels of ecosystem health. Comp. Immunol. Microbiol. Infect. Dis. 36, 333-342. doi: 10.1016/j.cimid.2012.11.007

Starck, J. M., and Ricklefs, R. E. (1997). Avian growth and development: evolution within the altricial- precocial spectrum, Oxford Ornithol. Ser. 8, 1-12.

Stokes, W. S. (2004). Selecting appropriate animal models and experimental designs for endocrine disruptor research and testing studies. ILAR J. 45, 387-393. doi: 10.1093/ilar.45.4.387

Sullivan, K. M., Marteinson, S. C., Letcher, R. J., Bird, D. M., Ian, J., Shutt, J. L., et al. (2013). Changes in the incubation by American Kestrels (Falco sparverius) during exposure to the polybrominated diphenyl ether (PBDE) mixture DE-71. J. Toxicol. Environ. Health A 76, 37-41. doi:10.1080/15287394.2013. 829759

Touart, L. W. (2004). Factors considered in using birds for evaluating endocrinedisrupting chemicals. ILAR J. 45, 462-468. doi: 10.1093/ilar.45.4.462

Toxicity testing methods. (2013). Available online at: http://www.eoearth.org/ view/article/156673

UNEP. (2009). Stockholm Convention on Persistent Organic Pollutants (POPs). Stockholm, UNEP. (Accessed April 24 2015).

Van den Steen, E., Covaci, A., Jaspers, V. L. B., Dauwe, T., Voorspoels, S., Eens, M. et al. (2007). Accumulation, tissue-specific distribution and debromination of decabromodiphenyl ether (BDE 209) in European starlings (Sturnus vulgaris). Environ. Pollut. 148, 648-653. doi: 10.1016/j.envpol.2006.11.017

Van den Steen, E., Eens, M., Covaci, A., Dirtu, A. C., Jaspers, V. L. B., Neels, H., et al. (2009). An exposure study with polybrominated diphenyl ethers (PBDEs) in female European starlings (Sturnus vulgaris): toxicokinetics and reproductive effects. Environ Pollut. 157, 430-436. doi: 10.1016/j.envpol. 2008.09.031

Vermeulen, A., Müller, W., Matson, K. D., Irene Tieleman, B., Bervoets, L., and Eens, M. (2015). Sources of variation in innate immunity in great tit nestlings living along a metal pollution gradient: an individual-based approach. Sci. Total Environ. 508, 297-306. doi: 10.1016/j.scitotenv.2014.11.095

Weaver, J. D., and Cade, T. J. (eds.). (1985). Falcon Propagation: a Manual on Captive Breeding. Ithaca, NY: The Peregrine Fund Inc. 
Woodruff, T. J. (2011). Bridging epidemiology and model organisms to increase understanding ofendocrine disrupting chemicals and human health effects. J. Steroid Biochem. Mol. Biol. 127, 108-117. doi: 10.1016/j.jsbmb.2010.11.007

Conflict of Interest Statement: The author declares that the research was conducted in the absence of any commercial or financial relationships that could be construed as a potential conflict of interest.
Copyright (c) 2015 Jaspers. This is an open-access article distributed under the terms of the Creative Commons Attribution License (CC BY). The use, distribution or reproduction in other forums is permitted, provided the original author(s) or licensor are credited and that the original publication in this journal is cited, in accordance with accepted academic practice. No use, distribution or reproduction is permitted which does not comply with these terms. 